\title{
Correction to: Eastern Japanese Dictyostelia Species Adapt While Populations Exhibit Neutrality
}

\section{Shun Adachi ${ }^{1}$}

Published online: 19 August 2020

○) Springer Science+Business Media, LLC, part of Springer Nature 2020

Correction to: Evol Biol (2015) 42:210-222

https://doi.org/10.1007/s11692-015-9312-0

The original version of this article unfortunately contained an error. The authors would like to correct the error with this erratum.

Sampling in May 2012 was actually not in May, but in April 2012. May was a missing value. Therefore, we would like to modify the text as follows:

1. In Materials and Methods, Point Quadrat analysis; "In order to observe population dynamics, soil samples were collected every month from May 2012 to January 2013." would be "In order to observe population dynamics, soil samples were collected in April 2012 and in every month from June 2012 to January 2013."

2. In Fig. 4a, "May" would be "April". In Fig. 4b, PpWE5, PpWW5 would be PpWE4, PpWW4.

The labelling difference does not affect any discussions in the text.

Publisher's Note Springer Nature remains neutral with regard to jurisdictional claims in published maps and institutional affiliations

The original article can be found online at https://doi.org/10.1007/ s11692-015-9312-0.

Shun Adachi

f.peregrinusns@mbox.kyoto-inet.or.jp

1 Medical Research Project, Institute of Health Biosciences,

The University of Tokushima Graduate School, 3-18-15

Kuramotocho, Tokushima 770-8503, Japan 